\title{
HISTORIA HISTÓRICA DE LA FILOSOFÍA E HISTORIA FILOSÓFICA DE LA FILOSOFÍA: EL PROBLEMA DEL NUEVO CONOCIMIENTO
}

\author{
Miguel Saralegui ${ }^{1}$ \\ Ikerbasque/Universidad del País Vasco
}

Recibido: 30.12.2018 - Aceptado: 09.08.2019

\begin{abstract}
RESUMEN
En el siguiente artículo se intentará mostrar la relación que mantienen dos variedades de la historia de la filosofía con en el concepto de investigación. La distinción entre investigación intensiva e investigación extensiva trata de captar dos prototipos diferentes de investigación en historia de la filosofía. En primer lugar se muestra que estas modalidades están determinadas por el carácter híbrido del concepto de historia de la filosofía y por la relación con el canon filosófico. Posteriormente se explican las características particulares de la investigación intensiva y extensiva insistiendo en la dependencia de todas las prácticas de investigación en historia de la filosofía de estas dos formas prototípicas. Por último, son presentadas algunas conclusiones que permiten pensar una relación más armónica entre investigación histórica y actividad filosófica.
\end{abstract}

Palabras clave: historia de la filosofía; historia; filosofía; investigación intensiva; investigación extensiva.

\begin{abstract}
This article focuses on the relation of two varieties of history of philosophy and the concept of research. In this paper are distinguished two different prototypes of research in the frame of history of philosophy, the intensive and the extensive. In the first part is claimed that the hybrid character of the concept of history of philosophy, on the one hand, and the relation with the canon, on the other hand, determine these forms research. Then, the main features of the intensive and the extensive researches are explained and it is showed that all practices of research in the field of history of philosophy depend on this two prototypes. Finally some conclusions are provided in order to consider a much balanced relation between historical research and philosophical activity.
\end{abstract}

Keywords: history of philosophy; history; philosophy; intensive research; extensive research.

\footnotetext{
${ }^{1}$ miguelsaralegui@gmail.com
} 


\section{LA BATALLA DE LAS HISTORIAS DE LA FILOSOFÍA}

Por su naturaleza dual, la historia de la filosofía se puede entender en un sentido más histórico y en otro más filosófico. Si el concepto permite de modo natural la posibilidad de una historia histórica de la filosofía y otra historia filosófica, la convivencia ha sido mucho menos pacífica de lo que la composición mixta del concepto permitía prever. Se trata de un enfrentamiento bastante agrio. Si la historia histórica de la filosofía ha sido algo más moderada en sus reivindicaciones y suele aceptar la denominación de historia de las ideas, la historia filosófica de la filosofía ha ofrecido un juicio bastante severo sobre el valor del conocimiento que la disciplina hermana podía alcanzar. A pesar de su mayor moderación retórica, también a la historia histórica de la filosofía le cuesta admitir el valor epistemológico de la otra.

A pesar del tono normativo de la disputa, el resultado del enfrentamiento ha sido de empate. Ambos tipos de historias de la filosofía siguen escribiéndose, de manera impermeable a las críticas realizadas por la otra concepción de historia de la filosofía. Aunque en realidad nadie escribe una historia puramente histórica de la filosofía ni una historia netamente filosófica, los motivos de esta gradualidad son muy diversos y no se debe a que las críticas realizadas hayan corregido los respectivos puntos de vista. A pesar de la completa apología que Hegel le dedica a la historia filosófica de la filosofía, las mismas Lecciones sobre historia de la filosofía no siguen al pie de la letra la metodología descrita en las páginas introductorias y son mucho más históricas y eruditas de lo que la prescripción filosófica hacía prever.

Si el empate ha permitido que ambas perspectivas existieran y se desarrollasen, la autocomprensión de las ciencias humanas, como saberes que se justifican principalmente tanto social como existencialmente por su aportación a la investigación, ha introducido nuevas perspectivas a esta vieja disputa. En esta presentación, se quiere mostrar la relación que el concepto de investigación como aumento metódico del conocimiento mantiene con ambas variedades de la historia de la filosofía. Dadas las diferencias irreconciliables entre ellas, no puede extrañar que la investigación se dé en estas dos ramas de la historia de la filosofía de manera muy diversa. Si no se tiene clara esta profunda variedad, se corre el riesgo de acabar considerando verdadera investigación solo a una de estas prácticas. A pesar de que se puede 
pensar que la causa de esta reducción es el proyecto contemporáneo de ofrecer un solo concepto de investigación para todas las áreas del saber, esta incomprensión posee raíces más profundas. La condena de un tipo de investigación en historia de la filosofía se construye en muchos casos con los mismos argumentos que, desde hace dos siglos, una rama de la historia de la filosofía utiliza para criticar el valor de la otra.

Por este motivo, será útil explicar cuáles son las dos modalidades prototípicas de investigación en historia de la filosofía. Denominaré a estas dos maneras de realizar investigación en historia de la filosofía como intensiva y extensiva. Con una actitud más descriptiva que prescriptiva, quiero dar cuenta de los dos modos fundamentales en que se divide la investigación en historia de la filosofía. En primer lugar, mostraré que estas dos modalidades quedan determinadas por dos conceptos previos: el carácter híbrido del concepto de historia de la filosofía y la relación con el canon filosófico. Posteriormente, explicaré las características particulares de la investigación intensiva y extensiva. A su vez insistiré en que todas las otras prácticas de la investigación en historia de la filosofía dependen de estas dos variedades principales. Por último, ofreceré algunas conclusiones que buscan contener el desagrado que ciertos tipos de investigación en historia de la filosofía provocan en la academia de la filosofía, lo cual puede conducir a una relación más armónica entre investigación en historia de la filosofía y actividad filosófica. Frente a la actitud habitual que enfrenta a estas dos variedades de la historia de la filosofía, el principio inspirador de este trabajo reconoce las posibilidades epistemológicas de ambas ramas de la historia de la filosofía y, por tanto, de ambos tipos de investigación.

\section{LOS TIPOS DE HISTORIA DE LA FILOSOFÍA Y EL CANON DE LA FILOSOFÍA}

La disciplina de la historia de la filosofía obtiene sus nuevos conocimientos a través de dos tipos de investigación: el intensivo y el extensivo. Antes de detallar las características particulares de estos dos paradigmas, se debe apuntar las causas de esta tipología dual. Esta variedad surge por dos motivos: en primer lugar, es consecuencia de la naturaleza mixta de la historia de la filosofía; en segundo lugar, de la diferente manera de relacionarse con el canon.

En principio, la contradicción entre las exigencias de la investigación intensiva y la extensiva puede parecer chocante, pues ambas permiten adquirir nuevos conocimientos de modo correcto. Sin embargo, esta situación 
no es del todo anómala, si se tienen presentes las características esencialmente contradictorias de los componentes de la historia de la filosofía. La historia de la filosofía es el resultado de un proceso de hibridación de dos ciencias -la historia y la filosofía- que se relacionan con lo temporal de modo opuesto: la primera estudia la realidad sub specie temporis, le interesa lo que ya no es, mientras la segunda la examina sub specie aeterni, le preocupa lo que siempre ha sido y será. En su definición del concepto de historia de la filosofía, Hegel expone esta contradicción de modo paradigmático: "La historia expone lo mudable, lo que se ha hundido en la noche del pasado, lo que ya no existe; y el pensamiento, cuando es verdadero y necesario [...], no es susceptible de cambio" $(1996,11)$. Incluso si la postura de Hegel parece anticuada a una filosofía contemporánea que mira con sospecha la posibilidad de un conocimiento atemporal, se puede reformular esta oposición entre historia y filosofía a través del término "mentalidad", propuesto por Schopenhauer en su clásica y repetitiva crítica del valor epistemológico de la historia (2003, 490-498). ${ }^{2}$ La historia y la filosofía reproducirían dos mentalidades, dos tipos de psicología del conocimiento. La historia y la filosofía responden a actitudes de comprensión del mundo fundamentalmente opuestas.

Para la mente historicista, el detalle, lo particular y la minucia, cuentan con una gran importancia. Existe una ambivalencia en aquello que la historia conserva: si está segura de su verdad, no lo estará jamás de su relevancia o valor. Por esta ambivalencia se puede considerar a la historia un saber tímido (¿tendrá valor lo que guardo?) y tolerante (por si acaso guardemos todo). El defecto psicológico típico de esta mentalidad sería el síndrome de Diógenes. Como claramente ocurre en amplios sectores de la historiografía contemporánea, puede que al historiador le interese el descubrimiento de estructuras permanentes, incluso si esta operación intelectual tiene poco que ver con las tareas habituales de la historiografía tradicional. ${ }^{3}$ Sin que deba suponer un desdoro para su capacidad empírica como historiador, habrá que decir que este tipo de historiador, quizá el más común en los departamentos de Historia en la actualidad, se ha acercado al filósofo, lo cual no debería causar ningún escándalo en la medida que el filósofo lleva aproximándose al historiador desde hace dos siglos.

Por otra parte, la mente filosófica es mucho más ambiciosa. También quiere conocerlo todo, pero en un sentido antes cualitativo que cuantitativo.

2 "En esto se basa la contraposición entre la mentalidad filosófica e histórica: aquella quiere fundamentar, esta quiere relatar hasta el fin" (Schopenhauer 2003, 493).

3 Cfr. R. Koselleck, "Sobre la necesidad teórica de la ciencia histórica" in Prismas. Revista de historia intelectual, XIV, 2010, pp. 137-148 and R. Koselleck, Sentido y repetición en la historia, Hydra, Buenos Aires, 2013. 
Desprecia el detalle y el acontecimiento en sí mismos, como mucho los rescata como reflejos o rastros de una idea más universal y perenne. Si la historia recolecta, la filosofía criba. Si la historia es una gran mochila de contenidos abigarrados, a la filosofía no le interesa el número de las pertenencias, sino su exquisitez: se conforma con un puñado de piedras preciosas. A la ambiciosa y significativa filosofía, la historia le puede reprochar su incerteza: normalmente quiere mucho más de lo que puede. Por otra parte, si la historia se pierde en la multitud caótica de lo fáctico, en su mejor momento la filosofía puede jactarse de haber conseguido un gramo de significado.

Alguna de las incomprensiones que produce la historia de la filosofía en la academia contemporánea se debe al olvido del carácter inarmónico y excepcional del vínculo entre estas dos mentalidades. Al menos a quienes han sido educados como filósofos en el mundo hispanófono, se les ha repetido tanto los ideales historicistas y hegelianos que se ha perdido conciencia del carácter imprevisible y contradictorio de esta disciplina. Se ha dejado de percibir la incomodidad existencial de esta unión. ${ }^{4}$ La historia de la filosofía es un saber esencialmente extravagante, pues reúne dos actitudes básicas contrapuestas: la que busca comprender al mundo en su variabilidad (historia) y la que busca comprender al mundo en su estabilidad (filosofía). Si se admite que existe esta oposición casi psicológica entre estos dos modos de comprender el mundo, será más fácil de entender cómo es posible que, a partir de una misma disciplina, se desarrollen prácticas intelectuales y tipos de investigación tan diferentes. Si se pasa por alto la complejidad de este vínculo, la heterogeneidad de los nuevos conocimientos aportados por la investigación intensiva y extensiva de historia de la filosofía parecerá injustificable.

La división entre investigación intensiva y extensiva es consecuencia analítica de la identidad dual de la historia de la filosofía. Dada la contradictoria naturaleza de estos dos componentes, es casi necesario que exista una rama de la historia de la filosofía más histórica y otra rama más filosófica. Aunque la bibliografía distingue esta doble actividad historiográfica, de modo habitual se concede solo a esta última práctica el título de historia de la filosofía, mientras que se suele conferir otra designación -historia de las ideas, historia intelectual- a la versión más histórica (Morgan 1987, 718). Se puede decir que la crítica que la historia filosófica de la filosofía le reserva a la historia histórica de la filosofía reproduce la crítica que tradicionalmente

4 Ver: Mondolfo, 1960, 28. Entre otros y, con una obra especialmente brillante, ha reforzado el concepto hegeliano de historia de la filosofía: "la constitución y la esencia de cualquier realidad se encuentra y se revela sobre todo en el proceso de formación". 
los filósofos han dirigido a la historia (Aristóteles, Schopenhauer, Nietzsche). Si la mente filosófica puede aceptar en abstracto la existencia del tipo psicológico historicista, la tolerancia se acaba cuando esta mentalidad se inmiscuye en áreas en principio reservadas a la filosofía. Por este motivo, si puede existir una reconciliación entre historia y filosofía, esta es más difícil cuando se opone la historia de la filosofía histórica a la historia de la filosofía filosófica.

Además de esta primera oposición, para entender la distinción intensiva-extensiva, se necesita el concepto de canon. Si las dos subdisciplinas dependen analíticamente de los componentes de la historia de la filosofía, el canon es una creación cultural mucho más azarosa y reciente. Si el concepto de historia de la filosofía obliga a la existencia de una historia histórica y de una historia filosófica, sin embargo, no determina la existencia de un canon. Podría haber habido historia de la filosofía sin canon. La historia histórica de la filosofía se relaciona con el canon de manera extensiva: quiere estudiar qué hay más allá del canon. La historia filosófica de la filosofía estudia el canon de modo intensivo: quiere pulirlo, conocer perfectamente qué se conserva dentro de él. En conformidad con mi postura, es indiferente si el canon responde a motivos azarosos o a cualidades intrínsecas. Para la postura que esbozaré en este ensayo no es necesario pronunciarse sobre los motivos por los que se suele justificar la relevancia epistemológica y filosófica del canon.

A diferencia de otras ramas de la historia en las que el concepto de canon ha quedado obsoleto, para la mayoría de los filósofos y los historiadores de la filosofía sigue resultando un instrumento popular y aceptado, incluso necesario. Como ha recordado Manzo (2017, 127), el canon ha sido capaz de sobrevivir a la muerte del autor. El mismo Hegel, cuyo concepto de historia de la filosofía como progreso cognoscitivo parecía vetar cualquier rasgo de individualidad, acepta el canon a través de un concepto muy particular, el del "héroe filosófico": "los héroes de la razón pensante» cuyas "creaciones son tanto mejores cuanto menos imputables son, por sus méritos o responsabilidad, al individuo" $(1996,8)$.

¿Qué significa canon? En primer lugar, al igual que en el resto de las ciencias humanas, el canon filosófico tiene una dimensión informativa: reúne a quienes son social y académicamente considerados los miembros más representativos de una disciplina. A diferencia de lo que ocurre en otras ciencias humanas en las que el canon tiene una función puramente informativa, en el canon de la historia de la filosofía los filósofos suelen depositar mayores esperanzas. Si el Cid campeador pertenece indudablemente al canon de la literatura española, pocos historiadores de la literatura española 
estarán inclinados a afirmar que esta obra anónima es de mejor calidad literaria que una novela de Fernando Aramburu o un poema olvidado de Gabriel Aresti (si es que estos dos nombres no pertenecen al canon de la literatura española). En cambio, el historiador de la filosofía tiende a pensar que el filósofo incluido en el canon es mejor filósofo que el no incluido. Además, el canon filosófico posee una tercera virtud, la cual no creo que sea compartida por el canon de ninguna otra disciplina humanística. Si es perfectamente extravagante que un profesor de literatura española defienda que, tras estudiar el canon literario español, el alumno se convertirá en un buen escritor en lengua castellana, muchos profesores de filosofía defenderán que, después de estudiar el canon filosófico, el alumno se habrá convertido en un buen filósofo. A pesar de su extravagancia, se trata de una postura bastante extendida. El siguiente testimonio de Alejandro Llano es representativo de la postura de muchos profesores de filosofía (creo que no solo de ámbito hispanófono). Para saber filosofía, “debe usted leer a los pensadores clásicos [...]. Son seis. [...] Platón, Aristóteles, San Agustín, Tomás de Aquino, Kant y Hegel. Lo mejor es seguir este orden, porque cada uno supone a los anteriores" (Llano 2008, 331).

Otro tema que merece destacarse es el de la historicidad del canon, la cual suele ser recordada por los teóricos de la historia de la filosofía: "los cánones son móviles y contingentes. Se pueden desarmar y armarse nuevamente de otra manera" (Llano 2008, 125). A pesar de que desde un punto de vista ontológico nadie puede dudar de esta postura (Dios no creó el canon al octavo día), desde un punto de vista cultural, educativo, filosófico y también histórico, el canon se nos presenta como un objeto estable, como esos artefactos que acompañan la vida del hombre contemporáneo sin que este sienta que son invenciones muy recientes. Salvo aquellos raros licenciados en filosofía con intereses metódicos por la historia de la filosofía, la mayoría siente que es un acontecimiento perfectamente natural que unos pocos hombres hayan conseguido oligopolizar una disciplina con una trayectoria de veinticinco siglos de existencia adulta. Creo que ni siquiera les causa sorpresa la escasez relativa del canon filosófico, pues los héroes-filósofos conforman una nómina mucha más corta que la de los héroes-literatos, los héroes-artistas y, por supuesto, los héroes-militares y los héroes-políticos. La misma escasez de personal que caracteriza a la historia de la filosofía la acerca a la historia de la religión. La división entre autores canónicos y no canónicos se presenta todavía hoy con completa naturalidad, incluso por aquellos que la consideran una lente deformadora. El mismo Ortega acuña una metáfora original, la de cima-valle, para recordar que, a pesar de su ilegitimidad historiográfica, la distinción fundamental en la historia de la filosofía sigue siendo la 
de canónico-no canónico: “Aun juntando todo eso no sería una historia de la filosofía, como la orografía no es solo la ciencia de las cimas. La montaña reclama el valle" (Ortega 2006, 137).

¿Cómo logra el canon esta misteriosa estabilidad? Ciertamente el extremo de que los héroes-filósofos pertenecen al canon solo por una cualidad puramente personal y biográfica es indefendible. Son descubrimientos temáticos y logros filosóficos (la originalidad y la precisión argumentativa) que les entregan esta posición. Se considerará a Platón canónico por su metafísica, a Aristóteles por su capacidad para distinguir y sistematizar, a Kant por su epistemología. A pesar de la razonabilidad y deseabilidad de este tipo de justificación, no se deben menospreciar el peso de elementos puramente biográficos y tradicionales en la configuración del canon, pues no existe subdisciplina histórica más alejada de la filosofía que la biografía. Curiosamente en su elemento biográfico se da de modo especialmente interesante la combinación entre mutación y estabilidad del canon. Es correcto afirmar que el canon "es un índice de las preocupaciones de los filósofos del presente y de cómo ellos se dirigen al pasado remoto o reciente" (Llano 2008, 136). Sin embargo, estas preocupaciones contemporáneas apenas tienen efectos sobre los miembros estables del canon. La relectura contemporánea del canon lleva a estudiar a autores canónicos desde perspectivas, intereses y problemas actuales más que a estudiar a autores diferentes y extracanónicos. A veces no se recuerda con suficiente claridad que el carácter dinámico del canon es más adjetivo que sustantivo. Si se sigue estudiando a Kant, ya no se lo estudia por su epistemología, sino por su teoría del juicio y hasta por su doctrina de la locura o de la sexualidad. Si se estudia la imagen de la mujer en la obra de Maquiavelo, no se debe a que este autor haya defendido ideas especialmente interesantes sobre la condición femenina, sino a que el nombre canónico despierta interés en los historiadores de la filosofía incluso sobre aquellas opiniones y pensamientos que no se vinculan directamente a su condición de canónico. ${ }^{5}$ Tom Sorell ha descrito otra experiencia que solo puede ser explicada desde la estabilidad biográfica del canon: la del "antihéroe" $(2001,113)$. La inclusión de un antihéroe demuestra la victoria de lo biográfico y particular sobre lo general y lo filosófico. ¿Qué sentido tiene seguir incluyendo a un pensador como Descartes en el canon cuando los principales exponentes de la filosofía contemporánea lo usan como caricatura, cuyas ideas carecen del más mínimo valor filosófico? Este peso de lo biográ-

${ }^{5}$ Ver: Pitkin 1984. 
fico y hasta de lo nominal -ciertos nombres nos atraen de modo canónicamente misterioso- vuelve a confirmar que, si metafísicamente el canon es artificial, nos relacionamos con él como si fuera natural.

¿Cuál es la relación de los conceptos de intensión y extensión con el canon? La investigación intensiva ambiciona penetrar en el canon. Quiere obtener un nuevo conocimiento a través de la profundización en temas y autores canónicos: obtener un conocimiento más preciso, más pulido, que ambiciona incluso perfeccionar el canon. Idealmente, se estudiará al autor canónico por aquella idea, por aquel libro que le hace único y no por todas aquellas otras en las que no se distingue de cualquier otro pensador de su época. Debido a la naturalidad de que goza el canon en la enseñanza de la filosofía, se trata de un deseo sumamente natural: se ambiciona conocer mejor un pasado que sigue considerándose modélico para entender y hacer filosofía en el presente.

La investigación extensiva, por otra parte, no se desentiende del canon. También lo toma como límite, pero no como punto de llegada, sino de partida. Sin embargo, si la investigación intensiva se concentra en él, la extensiva se desplaza más allá de sus fronteras. Se podría utilizar la metáfora del ciudadano: tanto la investigación intensiva como la extensiva son ciudadanas del mismo país. Son diferentes porque, mientras la primera decide residir en la patria de nacimiento, la segunda prefiere vivir lejos de ella, aunque, en principio, sin voluntad de renunciar a su nacionalidad. La investigación extensiva puede ser un emigrante patriótico. No desea ampliar el canon ni desacreditarlo, sino solo conocer lo que existe fuera. Es posible también que su interés por lo extracanónico le puede llevar a rechazar el canon dominante y llegar a la convicción de que una historia milenaria y plural no se puede concentrar en las ideas de un puñado de pensadores. A este historiador extensivo a veces lo inspira un cierto populismo historiográfico: no acepta que la vocación por la filosofía, en sí misma universal, haya sido tan inequitativamente repartida.

\section{CARACTERÍSTICAS DE LA INVESTIGACIÓN INTENSIVA}

Si las dos variedades de la investigación en historia de la filosofía dependen de su relación con el canon, es momento de analizar sus características distintivas. ¿Cómo puede definirse la investigación intensiva? La investigación intensiva se caracteriza por estudiar el pasado de la historia de la filosofía de modo filosófico y centrado en aquellos temas por los que unos determinados autores pertenecen al canon. Propiamente no quiere conocer más co- 
sas que las incluidas en el canon, sino conocerlas mejor. La investigación intensiva en historia de la filosofía contempla de manera intensiva y filosófica el canon. Lógicamente existe la posibilidad de una investigación filosófica de autores y temas extracanónicos. Sin embargo, de modo fáctico, este tipo de investigación es poco frecuente y, como explicaré, cuando se da, se suele considerar, con algún grado de imprecisión, como investigación extensiva.

Para entender la práctica de la investigación intensiva en historia de la filosofía, es necesario detallar las características de la historia filosófica de la filosofía. La investigación intensiva es la manera como la historia filosófica de la filosofía adquiere nuevos conocimientos. Esta se considera más cercana a la filosofía que a la historia. Es una actividad tan intelectualmente ardua y tan idealmente parecida a la génesis de la filosofía que puede llegar a confundirse con ella. Se trata de la vieja postura hegeliana de la "historia interna de la filosofía", según la cual "el estudio de la historia de la filosofía es el estudio de la filosofía misma" (Hegel 1996, 34). Por este motivo, se suele reivindicar que la historia de la filosofía "puede ser una forma de actividad filosófica en sí misma” (Morgan 1987, 726-727). Los historiadores filosóficos de la filosofía pueden concebirse antes como filósofos que como historiadores de la filosofía.

En el pensamiento posthegeliano, ha sido tan común la aceptación de la identidad entre la filosofía y la historia de la filosofía que muchos historiadores filosóficos de la filosofía pueden llegar no solo a considerar irrelevante el aspecto histórico de su identidad profesional, sino a ser inconscientes de él.

La novedad ocupa un lugar muy pequeño en las ambiciones de la historia filosófica de la filosofía. No le interesa primariamente encontrar aspectos olvidados de la historia de la filosofía, sino cómo las ideas fundamentales de un autor canónico pueden ser relevantes para el desenvolvimiento del presente filosófico. El carácter secundario que tiene el detalle en esta reconstrucción del pasado filosófico le permite al historiador filosófico de la filosofía discurrir sobre las ideas de más de un autor canónico de ese pasado. Por este motivo, puede escribir obras de carácter sintético y global. En cierta medida, la ambición filosófica con que se dirige a la historia le obliga estudiar a todos los autores canónicos que han disputado sobre el punto que le parezca filosóficamente relevante. En consecuencia, la enciclopedia, el manual de historia de la filosofía o una obra comprensiva que resuma las doctrinas canónicas son los géneros donde este concepto de historia de la filosofía se expresa mejor. 
Esta versión de la historia filosófica de la filosofía encuentra su mejor justificación en un mundo, que ya no es el nuestro, que insiste en la dimensión pedagógica y formativa de la filosofía. Por este motivo, la historia filosófica de la filosofía se encuentra más cómoda en el campo de la transmisión del conocimiento (la educación) que en el de la creación (la investigación). Existe una larga tradición que insiste en que la filosofía se debe aprender a través del estudio de la historia de la filosofía, siempre que sea entendida de modo canónico y filosófico. Incluso quienes no comparten sus presupuestos hegeliano-marxistas podrán estar de acuerdo con la postura de Mondolfo según la cual para comprender un concepto se necesita conocer su historia:

Toda investigación teórica, por lo tanto, que quiera encontrar mayor seguridad en su camino, supone y exige como condición previa una investigación histórica referente al problema, a su desarrollo, a las soluciones que se han intentado del mismo (Mondolfo 1960, 28).

El historiador de la filosofía del Renacimiento James Hankins ha criticado este uso pedagógico y unilateral de la historia. Esta historia de la filosofía solo se interesará por aquellas ideas pasadas que consiguen mantener protagonismo en el debate filosófico contemporáneo:

Buscar solo a compañeros que nos pueden acompañar en conversaciones actuales, desechando a aquellos que hablan en lenguas filosóficas diferentes, inevitablemente limita el debate. Convierte a la filosofía en un monólogo anacrónico; solo hablamos con nosotros mismos (Hankins 2007, 341).

Si desde un punto de vista investigativo e historiográfico esta objeción es pertinente, es, al mismo tiempo, abstracta, pues no tiene en cuenta que la justificación habitual de la historia de la filosofía se da en un plano pedagógico y no en el de la innovación investigativa o la precisión historiográfica. Solo este diálogo interesado con el pasado, casi condenado al anacronismo, permite que la historia de la filosofía desempeñe un papel central en la formación de los futuros filósofos, al menos en muchas tradiciones filosóficas. Es poco plausible defender que los aprendices de filósofos deban formarse desocupándose de autores y temas consagrados, para centrarse en temas, textos y autores olvidados, de cuyo valor filosófico, por su misma novedad, se ha de estar poco seguro. Es muy probable que, si la historia de la filosofía se deshiciera completamente de esta consideración canónica y filosófica de su pasado, se obtendría una perspectiva historiográficamente más precisa. Sin embargo, el coste de esta transacción sería altísimo: la historia de la filosofía ocuparía un lugar cada vez más marginal en la disciplina de la filosofía y en la formación del filósofo. 
De acuerdo con la definición de la historia filosófica de la filosofía, los mismos historiadores canónicos de la filosofía pueden reconocer que su trabajo no cumple los criterios de la investigación. Por este motivo, más allá de estrategias propias de la sociología profesional, su interés no estribará en ser reconocidos como investigadores, sino en recordar la relevancia filosófica de este tipo de historia filosófica, así como insistir en la insignificancia de trabajos que sí cumplen los criterios de investigación. Si esta historia intensiva y canónica de la filosofía no podrá ser validada como investigación, existe otra variedad de historia filosófica de la filosofía que sí puede cumplir estas exigencias.

La posibilidad lógica de que exista una investigación intensiva de la historia de la filosofía depende de que exista un objeto canónico que, hasta el momento en que se emprende la investigación, no haya sido completa ni adecuadamente estudiado. Más que pensar que la doctrina canónica sea absolutamente desconocida para el público filosófico, el investigador canónico considera que no se ha difundido una imagen adecuada y precisa de una doctrina canónica. Hasta mi investigación, la teoría de la obligación en Hobbes no había sido adecuadamente entendida. El investigador canónico se concentrará en los detalles del corpus de Hobbes sobre este punto mal comprendido para demostrar que la imagen tradicional era imprecisa y que él aporta novedad sobre un punto filosóficamente relevante. Es posible también que el investigador intensivo mantenga una relación más crítica con el canon, incluso cuando no se desvincule absolutamente de él. Puede afirmar que el motivo por el que un autor fue considerado canónico es equivocado. Hobbes fue considerado canónico por su teoría de la obligación cuando esta era perfectamente convencional. Habrá que estudiar al autor canónico por otro motivo, ya sea para desacreditar completamente el motivo que lo hacía canónico (lo importante es la teoría del cristianismo en Hobbes y no la de la obligación), ya para reinterpretar en una nueva clave la vieja atribución canónica (la importancia filosófica de la teoría de la obligación de Hobbes solo puede ser entendida de acuerdo con un aspecto de su cristianismo que había pasado inadvertido).

Si desde un punto de vista lógico la posibilidad de investigación intensiva en este sentido es admisible, es más difícil de justificarla en la práctica. ¿Por qué? Por una situación más histórica y fáctica que filosófica y conceptual. Si la posibilidad de la investigación intensiva era natural a comienzos del siglo XX, cuando los estudios sobre historia de la filosofía eran balbucientes, es mucho más difícil de justificar a comienzos del siglo XXI. En este momento del desarrollo del saber, cada autor y cada objeto canónico cargan a sus espaldas con una enorme biblioteca secundaria, donde se recogen todas 
las interpretaciones posibles. Parece difícil que una sola perspectiva relevante y completa sobre el concepto de lo político en Maquiavelo no haya sido percibida y difundida por uno de los cientos de académicos que en todas las lenguas occidentales escriben sobre él todos los años desde hace más de un siglo. Ciertamente, no se pueden excluir olvidos y errores en estas enormes bibliografías. Los estudiosos han podido malinterpretar durante cien años objetos canónicos. Sin embargo, parece que no se ha desatendido por completo ninguna perspectiva, como demuestra el hecho de que de cada autor canónico existen las más variadas corrientes interpretativas. Por esta acumulación que recae sobre todo objeto canónico, el investigador intensivo no puede presumir que su aportación es novedosa. Solo podrá defender que está ofreciendo una interpretación original tras haber realizado una justificación muy cuidadosa y completa. Si considera que su trabajo pertenece al campo de la investigación y como tal quiere que sea reconocida en la comunidad científica, debe justificar por qué su perspectiva canónica y filosófica ha pasado inadvertida tras cien años de investigación intensiva.

Si de modo habitual las posibilidades para que se alcance esta investigación son escasas y remotas, existen situaciones objetivas que pueden hacer la investigación intensiva no solo posible, sino hasta inevitable. Estos casos son excepcionales. En primer lugar, las interpretaciones precedentes carecían de herramientas necesarias para alcanzar la postura que ahora se propone (progresiva publicación de un corpus, descubrimiento de documentos privados). En segundo lugar, puede ocurrir que se llegue a la convicción de que un objeto canónico ha sido malinterpretado secularmente por una tradición hermenéutica con intereses espurios. El caso más famoso de esta novedad canónica puede ser el que protagoniza Werner Jaeger cuando afirma que, frente al edificio compacto que reivindicaba la lectura escolástica, a Aristóteles solo se le puede entender desde una perspectiva cronológica.

También hay malas prácticas asociadas a la investigación intensiva de la filosofía. Lamentablemente estas son muy frecuentes. Sus productos pueden ser publicados en muchas de las revistas más reconocidas por la comunidad de los investigadores. En primer lugar, la bibliografía de los objetos canónicos está rota en diferentes lenguas y tradiciones académicas que tienen mucha menos relación de lo que exige el camino de la ciencia. Puede existir una obra relevante y hasta conceptualmente idéntica sobre la teoría de la obligación en Hobbes escrita en polaco que sea desconocida al investigador intensivo. De este modo, al entender como novedosa su interpretación, el investigador simplemente está desconociendo que las principales ideas de su aportación habían sido expuestas treinta años antes de realizar 
su investigación. Si este caso puede resultar extravagante, la escasa atención que la academia anglófona presta a la bibliografía secundaria de tradiciones académicas cuya relevancia es indudable (académicos anglófonos que desconocen la investigación sobre Maquiavelo escrita en italiano) muestra que muchas publicaciones intensivas no cumplen los criterios más básicos de novedad metódica. La mayoría de los trabajos intensivos que se consideran investigación debería hacer esta advertencia: solo se tiene la seguridad de que el contenido de este trabajo es novedoso en relación con la bibliografía escrita en estas determinadas lenguas, las cuales no son equivalentes al número total de lenguas en que se realiza investigación sobre este tema. El noventa por ciento de las investigaciones realizadas por los investigadores del ámbito anglófono debería decir que sus trabajos pueden ser novedosos solo respecto de la bibliografía escrita en inglés. Por muy importante y muy superior que sea la bibliografía anglófona tanto cualitativa como cuantitativamente en la actualidad, esta situación no siempre fue así y, en muchos campos de la historia de la filosofía, sigue sin serlo. No se trata de una situación ni dramática ni anómala, si se tiene en cuenta el contexto actual de hiperproducción científica. El investigador no puede justificar la novedad de su aportación por un motivo muy sencillo: simplemente no puede tener en cuenta todas las contribuciones precedentes a su trabajo. En cualquier caso, este reconocimiento de la incapacidad de cubrir toda la bibliografía es mucho mejor que la costumbre de considerar irrelevante todo aquello que simplemente no se conoce.

Sin embargo, esta no es la peor práctica científica causada por la investigación intensiva. Si en este caso puede haber conocimiento relevante, aunque no investigación, existe una costumbre mucho más perjudicial desde un punto de vista cognoscitivo causada por la novedad que requiere la investigación. Debido a la dificultad de alcanzar los criterios de novedad que requiere la investigación y dada la importancia que la investigación posee en la carrera académica actual, a la investigación intensiva se le suele adosar una de las prácticas hermenéuticas más reprobables: atribuir de modo artificial a viejos textos canónicos lecturas tan novedosas como inverosímiles. No se trata, como ha apuntado Narbonne, de "lo impensado de un texto [impensé d'un texte]" $(2009,75)$, sino de pura arbitrariedad y extravagancia interpretativa. Cuando el historiador intensivo de la filosofía ofrece una interpretación que choca con las posibilidades hermenéuticas del texto canónico, la probabilidad de alcanzar una cierta novedad en un contexto superpoblado será mucho mayor. A causa de que se tiene que ofrecer una lectura nueva para justificar el carácter investigativo de este trabajo sobre Hobbes, se deforma el Leviatán, como cuando se defiende que en Hobbes la sociedad de 
naciones no se encuentra en estado de naturaleza, lo que queda desmentido por todos aquellos pasajes en los que el filósofo inglés describe las relaciones internacionales. Si en este caso se puede alcanzar novedad, se consigue a un precio muy alto: la de la total arbitrariedad hermenéutica.

Existe un último modo de plantear la investigación intensiva en historia de la filosofía. En este caso, el investigador va a la historia de la filosofía no solo con una ambición de reconstruir la argumentación de Hobbes desde un punto de vista histórico, sino también filosófico. Si a veces puede resultar difícil distinguir este trabajo de reconstrucción del puramente histórico, muchas veces este historiador de la filosofía no esconde su ambición, incluso si no suele ser plenamente consciente de su enormidad: reconstruir un argumento desde un punto netamente filosófico y creativo. A este respecto, muchos filósofos han hablado del "principio de caridad".

Desde un punto de vista filosófico y conceptual, la actitud defendida por el principio de caridad me parece perfectamente justificable. Uno va al pasado en busca de inspiración, pero de modo libre, no con un respeto total, hasta que el texto o el autor muestra una imperfección. Cuando el autor no cierra o simplemente no es convincente, el intérprete filosófico decide mejorarlo o pulirlo. Evidentemente los autores, también los canónicos, se equivocan, no repasan sus textos, son inconscientes de algunos errores, no ofrecen argumentaciones perfectas. ¿Dónde está el problema? Si filosófica y conceptualmente no hay problema en mejorar un argumento, tal problema es enorme desde un punto de vista histórico. El principio de caridad se puede utilizar de dos maneras. Si con este principio me limito a reconstruir una idea que está en el autor, de la que el autor canónico era consciente, incluso si no la expresó de la mejor manera, todavía estoy en el campo de la historia de la filosofía. Si, por otra parte, utilizo el principio de caridad para corregir alguna falla argumental que con toda seguridad lastra la argumentación original, entonces mi identidad y mi actitud intelectual ya no es la del historiador de la filosofía, sino la del filósofo a secas. En el momento en que corrijo un error, si mejoro la postura filosófica, deformo el documento.

Zarka, uno de los defensores más decididos de la historia de la filosofía entendida en un sentido filosófico, sostiene que esta historia filosófica deberá respetar el método histórico: "la especificidad de una historia de la filosofía que asume las exigencias de exactitud de la historia, por una parte, y que mantiene la especificidad de un sentido, de algo dado o de un valor o verdad filosófica, del otro" $(2001,25)$. No se debe preguntar a Zarka y, en general, al investigador caritativo por su deseabilidad, sino por su posibilidad. ¿Se pueden conciliar ambas exigencias? Por muy deseable que sea la conciliación, existen situaciones en las que es imposible. Si el principio de 
caridad nos lleva a afirmar algo que no estaba en el original, algo que el autor jamás pudo pensar o de lo que no pudo ser consciente, entonces el trabajo que se tiene delante ya no es histórico, sino filosófico, incluso si posee una inspiración histórica. De este modo, la idea perfeccionada del filósofo canónico ya no podrá ser considerada un resultado investigativo de la historia de la filosofía, sino de la filosofía. Para saber si esta postura puede ser investigación, se deberán aplicar criterios puramente filosóficos más que históricofilosóficos.

En consecuencia, frente a la exigencia de creación de nuevo conocimiento, el ejercicio intensivo de la historia de la filosofía tiende a fallar, lo que el anticuado historiador hegeliano y filosofizante de la filosofía debe juzgar antes como triunfo que como fracaso. Si el investigador intensivo, como expresión de la historia filosófica de la filosofía, se interesa por la historia de la filosofía debido a su carácter canónico, ¿por qué le habrá de disgustar no alcanzar una novedad que de alguna manera desmiente el motivo por el que la valoraba? Es tan esencial la mirada intensiva a la historia de la filosofía que, incluso si se llegase a un punto en que no pudiesen existir una combinación entre investigación y mirada intensiva -el día en que se alcanzasen interpretaciones completas de los autores canónicos en todos los temas filosóficamente relevantes-, los historiadores intensivos de la filosofía renunciarán sin problema al afán investigativo. La historia de la filosofía se convertiría en la repetición formativa de las interpretaciones mejor fundadas de los autores.

En ningún caso, la dificultad de la historia filosófica de la filosofía para completar los requerimientos de la investigación implica su exclusión de la filosofía como saber académico. Simplemente muestra que el espacio que esta subdisciplina de la historia de la filosofía merece en los estudios superiores, no se justificará por sus resultados investigativos. Si este fuese así, se estaría promoviendo en la mayoría de los casos un ejercicio de la investigación pobre y hasta corrupto. Se trata de un hecho simple. La relevancia y solidez del canon puede ser directamente contradictoria con las exigencias de la investigación. Si en nuestras clases repetimos una interpretación fundamentalmente acertada de La crítica de la razón pura, estaremos contribuyendo a la correcta comprensión de la teoría del conocimiento de Kant, sin obtener propiamente ningún nuevo conocimiento para la historia de la filosofía como disciplina que va acumulando nuevos conocimientos de modo metódico. Por supuesto, con esto no quiero promover que en el estudio universitario de la filosofía no se relean a los grandes clásicos, ni dejar de promulgar las interpretaciones más acertadas de Kant. En cambio, sí me parece irrenunciable aceptar que la relectura y divulgación de las obras canónicas 
no depende de su carácter investigativo salvo en ocasiones muy excepcionales.

\section{LA INVESTIGACIÓN EXTENSIVA EN LA HISTORIA DE LA FILOSOFÍA}

¿Cómo se puede describir la práctica extensiva de la historia de la filosofía? La relación de la investigación extensiva con la historia histórica de la filosofía es simétrica a la que la investigación intensiva mantiene con la historia filosófica de la filosofía. Idealmente, la historia histórica de la filosofía se entiende como una actividad analítica, recolectora, a la que le gustaría excluir de raíz toda interpretación. A diferencia del intérprete filosofante de la Crítica del juicio, esta se parece a ese monje que se dedicaba a transcribir libros para rescatarlos del olvido, incluso cuando no comprendía cabalmente el contenido del documento conservado. Lo domina la perspectiva del método histórico positivo y, como historiador de la filosofía, se identifica no tanto con el filósofo, cuanto con el historiador de la música o de la literatura, más conscientes de que, como historiadores, ni son Vivaldi ni Dante. Al carecer de un concepto definido de filosofía y aceptar un concepto intuitivo y nominal de ella (suele considerar filosofía todo texto que se consideró a sí mismo como filosofía), corre el riesgo de incluir dentro de la historia de la filosofía a pensadores, intelectuales o escritores a los que, desde una visión normativa, podría no corresponderles la denominación de filósofo.

Existe un nombre clásico para esta manera de concebir la historia de la filosofía: doxografía. Tan natural es esta mirada sobre el pasado de la historia de la filosofía, como habitual su denuesto entre los defensores de la historia filosófica de la filosofía. Hegel será su crítico más mordaz y sistemático. La despreciará por ser "materia de ociosa curiosidad", que consiste "saber una serie de cosas inútiles», "una ciencia harto superflua y aburrida, por mucha utilidad que [...] se creyese sacar de todo ese trasiego de pensamientos" $(1996,18)$. Considera que la inteligencia de un historiador histórico de la filosofía se parece más a la de un loro que a la de un animal racional: "Los autores de tales historias podrían compararse a animales, por cuyos oídos entran todos los sonidos de la música, pero sin ser capaces, naturalmente, de captar una cosa: la armonía de esos sonidos" $(1996,7)$. Le llegará a reprochar incluso que "no toma en serio la fe en el gobierno divino del universo" $(1996,39)$.

La fama de Diógenes Laercio, el gran doxógrafo de la filosofía de la Antigüedad, informa de la ambigua consideración de esta práctica. Si su gusto por la anécdota y la trivialidad de sus interpretaciones suelen hastiar al historiador de la filosofía antigua, su lectura es obligatoria. La misma falta de 
normatividad con la que Diógenes Laercio escribe La vida de los filósofos ilustres permite incluir una serie de ideas, pensamientos y actitudes que, si a Aristóteles -el historiador hegeliano de la filosofía antigua- no le parecían filosóficas, a otros lectores sí se lo pueden parecer. Por otra parte, la enorme cantidad de autores a los que Diógenes se refiere simplemente se habría condenado al olvido sin la acción de esta pluma frívola y periodística. Como Diógenes Laercio, el investigador extensivo en historia de la filosofía se dedica a estudiar a un autor relativamente olvidado -excluido del canon- con el mero deseo de dar a conocer una obra perdida, con una interpretación tendencialmente neutra, cuyo objetivo ideal consistiría en convertirse en paráfrasis. Es habitual que este trabajo no lo realicen filósofos, ni siquiera historiadores de la filosofía profesionales, sino, sobre todo, historiadores de la literatura y eruditos al margen de las profesiones académicas.

Se podría pensar que esta práctica extensiva y doxográfica de la investigación es realizada por los seguidores de los métodos propugnados por Quentin Skinner. Más allá de la Escuela de Cambridge, el potencial extensivo de cualquier método contextualista es evidente. Frente a una historiografía intensiva que se preocupa solo de un grupo muy reducido de autores, el contextualista quiere entender a Descartes o a Hegel como participantes de un debate intelectual, incluso si su postura puede ser más interesante y valiosa que la de sus contemporáneos. Sin embargo, a pesar de la inclinación extensiva de todo método contextualista, la mayor parte de la investigación de Skinner ha respetado las exigencias del canon y de la investigación intensiva. ${ }^{6}$

Si la investigación intensiva es difícil de alcanzar por el avance de la bibliografía secundaria en los últimos cien años, las condiciones para que se dé investigación extensiva son mucho más favorables. Esta facilidad se debe a que la bibliografía de la historia de la filosofía se ha concentrado en un grupo pequeño de autores canónicos. Se ha prestado tanta atención a los autores canónicos que muchos autores extracanónicos se encuentran casi completamente desatendidos. A veces esta desatención se debe a un escaso valor conceptual, otras a azares históricos, los cuales desmienten en buena medida la imagen racional y necesaria del curso de la historia de la filosofía. A diferencia del intensivo, el investigador extensivo puede completar con facilidad las primeras exigencias de la investigación: puede conocer toda la bibliografía primaria y secundaria para elaborar una imagen novedosa sobre un punto particular o una reinterpretación general del autor estudiado.

${ }^{6}$ Ver: Collins 2009. 
A pesar de la reivindicación tradicional del carácter formativo de la historia filosófica de la filosofía y de la investigación intensiva, existe una etapa de la formación del filósofo en la que la investigación extensiva posee una cierta ventaja también en un plano pedagógico.

Me refiero al momento en que el historiador de la filosofía se forma como investigador, es decir, cuando un estudiante de doctorado debe elaborar una tesis sobre un tema o un autor de la historia de la filosofía. En primer lugar, la investigación extensiva es valiosa en la medida en que aporta nueva información, incluso si no se conecta de modo directo con los grandes relatos de la historia de la filosofía (lo que debería llevar a revisarlos). Gracias a esta labor, podemos leer a autores que muchas veces seríamos incapaces de conocer, sobre todo si su obra se encuentra perdida en manuscritos o en alguna lengua desconocida (por esto, paradójicamente, una primera traducción se puede justificar de modo mucho fácil como nuevo conocimiento que la enésima interpretación del Dasein de Heidegger). Puede ser una dedicación intelectualmente modesta, pero es razonable como iniciación en la investigación, pues, al mismo tiempo que está segura de la creación de nuevo conocimiento, acepta implícitamente la variedad de la expresión filosófica y fomenta la tolerancia intelectual, lo que será más difícil que suceda cuando el joven investigador se inicia con el examen de obras de indudable influencia y valor filosófico como La fenomenología del espíritu o la Suma teológica. Es previsible que, al estudiar a un autor que le sobrepasa intelectualmente desde cualquier punto de vista, el joven investigador se convierta en un adepto y un partidario de las escuelas -aristotélica, tomista, kantiana o hegeliana-, que pueblan la filosofía en todas sus épocas y que interrumpa el diálogo filosófico de modo mucho más tajante que la erudición.

Por último, la doxografía es el limitado y realista puente por el que transita lo interdisciplinario. Por un lado, el objeto que se pone a disposición para este diálogo nunca puede ser tan sofisticado ni preciso como la labor actual y máxima de la dedicación. Por otro, las virtudes y las capacidades de este historiador puramente extensivo de la filosofía no son otras -y a veces solo son esas- que las que todo erudito en ciencias sociales y humanas debe tener. Sin embargo, la doxografía no solo permite la comunicación interdisciplinaria, sino también la intradisciplinaria, sobre todo en un momento histórico, como el actual, de superespecialización. Por ejemplo, solo la investigación extensiva podrá reunir a los historiadores de la filosofía de diferentes periodos. Un historiador de la filosofía antigua podrá comunicarse con un historiador de la filosofía moderna no a través de la imagen más sofisticada y actualizada de Platón, sino a través de una interpretación cercana a la paráfrasis. Como historiador de la filosofía de una época diferente a la antigua 
se está obligado a conocer a Platón de modo detallado, sin que sea exigible estar al día en interpretación de los pasajes más difíciles de los Diálogos.

Si la investigación extensiva en grado puro no consigue la sanción de los filósofos ni siquiera la aprobación de todos los historiadores de las ideas, existen grados intermedios entre la investigación intensiva y extensiva que sí gozan de mayor prestigio. Al menos dos tipos de investigación intermedias han conseguido la legitimación profesional dentro de la academia de la filosofía. La primera estudia a un filósofo que no pertenece al canon para mostrar que sus ideas son relevantes y a veces más penetrantes que aquellas propuestas por un filósofo que sí pertenece al canon. Se trata de la investigación filosófica y extracanónica antes señalada. Excepcionalmente, se conseguirá que un autor extracanónico pase a integrar el canon. Quizá sea Nicolás de Cusa el autor históricamente más marginal -sus obras no fueron editadas entre el siglo XVI y el XIX- donde el "impacto retrospectivo" sobre nuestra constitución del canon ha sido más claro (Manzo 2017, 134). La investigación que relaciona lo extracanónico con lo canónico suele tener resultados menos contundentes. Estudiamos a un escéptico ignoto para mostrar que su crítica del conocimiento es más sólida que la de Hume. Se trata de una mezcla de historia histórica de la filosofía (no considero el canon como objeto de investigación) con ambición filosófica del historiador de la filosofía (soy capaz de reformular el pensamiento de autor extracanónico de acuerdo con categorías canónicas).

Sin embargo, la mayoría de las investigaciones híbridas suelen tener ambiciones aun más modestas. Normalmente, se trata de estudios de precedencia histórica -el escepticismo antes de Hume- que buscan comprender mejor la obra del héroe-filósofo. En ambos casos, se trata de un tipo de investigación sumamente valioso desde una perspectiva tanto filosófica como enciclopédica -intensiva y extensiva-, pero difícil de llevar a cabo, pues exige tanto un alto nivel de cultura filosófica general como un notable grado de especialización en diferentes autores y periodos.

También estamos ante un concepto intermedio de investigación cuando se estudia a un filósofo canónico, pero por ideas y motivos diferentes a las que le granjearon este estatus. Por ejemplo, se estudia la teoría política de Kant, cuando, hasta ese momento, se consideraba que su mérito filosófico se sostenía sobre su epistemología. También practicamos esta investigación, cuando nos adentramos en el pasado filosófico para descubrir la opinión de un pensador canónico sobre cuestiones que hoy son relevantes, pero que en su día apenas ostentaban importancia. 
A su vez, analizar temas desconocidos de autores canónicos puede poseer una vocación más interpretativa o más parafrásica. Por un lado, este tipo de investigación puede resultar más cercano a la interpretación intensiva: nos servimos de esos textos descuidados para dar una imagen innovadora y completa de ese autor. Por ejemplo, hasta la fecha no se había reparado en la importancia de los argumentos republicanos de La falsa donación de Constantino de Lorenzo Valla y, al anotarlos, se demuestra que el principal propósito de este autor no es filológico, como se había creído, sino político. Se trata del mismo caso señalado antes del intérprete que considera que la teoría de la obligación de Hobbes solo se podía entender a través de su cristianismo. Por otro lado, este tipo de investigación puede tener una ambición puramente extensiva. Se extraen los pasajes de un autor acerca de una determinada cuestión sobre la que nunca publicó una obra independiente. Al reunir todo el material en que Schmitt escribe sobre la técnica, el estudioso edita la Filosofía de la técnica que este pensador jamás divulgó de modo autónomo. Aunque esta actitud puramente doxográfica debería recibir el mismo juicio con que se condena al erudito recolector, suele conseguir un mayor aprecio, quizá por el prestigio que el autor canónico le otorga. En consecuencia, no sorprende que esta práctica sea financiada por las instituciones de investigación, pues, al mismo tiempo que justifica de modo innegable su novedad, disimula su falta de ambición teórica gracias al prestigio del filósofo canónico.

¿A qué se debe entonces que la historia histórica de la filosofía y, en consecuencia, la investigación extensiva siga teniendo mala fama? A la aceptación de un principio hegeliano y racionalista: la historia de la filosofía tiene que ser filosófica. Se trata de una idea difícil de justificar (¿tiene que escribir una historia musical el historiador de la música?), pues no establece una diferencia entre el objeto de estudio (la filosofía) y el modo de estudio (la historia). ${ }^{7}$ Solo en un ambiente intelectual con una convicción hegeliana de fondo, se puede menospreciar la historia histórica de la filosofía y la investigación extensiva por realizar comúnmente una operación intelectual muy distinta a la filosófica. Del mismo modo que el filólogo necesita de la filosofía en su formación y el físico de matemáticas, no es de suyo rechazable que el filósofo necesite que una parte de su formación sea histórica, incluso si su contenido es poco filosófico.

7 Ver: Rabossi 2008, 150-151. El autor ha insistido en este punto: "nadie diría que quien escribe una historia del ciclismo es, por este hecho, un ciclista, ni que la persona que compone una historia de la química es, por esta razón, una química. Nadie diría que quien escribe una historia de la pintura es, por esta circunstancia, un pintor. Sin embargo, quien se dedica a historiar la filosofía es considerado, o reclama ser considerado, por este hecho un filósofo". 


\section{DE LA NECESIDAD NO INVESTIGATIVA DE LA HISTORIA FILOSÓFICA DE LA FILOSOFÍA A LA REVALORIZACIÓN DE LA HISTORIA HISTÓRICA DE LA FILOSOFÍA}

El desconcierto y hasta el malestar que la investigación causa en la academia de la filosofía contemporánea no está injustificado en el campo de la historia de la filosofía. Existen dos tipos de investigación muy diferentes, los cuales se consiguen a través de operaciones intelectuales casi opuestas. Sin embargo, esta diversidad del conocimiento proporcionado por la historia de la filosofía no representa una completa novedad, ni depende exclusivamente de la uniformización ejercida por un momento donde la investigación es el último motivo de justificar la existencia social de las humanidades. Al menos en parte, se trata de una actualización del antiguo enfrentamiento entre una comprensión histórica y otra filosófica de la historia de la filosofía.

Existe, sin embargo, un aspecto novedoso en esta disputa y en este malestar. La hermana pequeña, tantas veces menospreciada, de la historia de la filosofía se ha adaptado mejor a las exigencias contemporáneas de la investigación que la primogénita y orgullosa historia filosófica de la filosofía. En la mayoría de los casos, la investigación extensiva cumple mejor con los criterios de investigación, como conocimiento nuevo metódicamente creado, que la investigación intensiva, dependiente de una consideración filosófica de la historia de la filosofía. De disciplina acomplejada, la historia histórica de la filosofía se ha convertido en una rama más de las ciencias históricas gracias a la investigación extensiva. Más aún, se ha convertido también en una de las pocas justificaciones para que los historiadores de la filosofía puedan recibir también el título de investigador, la única credencial que permite sobrevivir al humanista en la sociedad contemporánea.

El reconocimiento de la historia histórica de la filosofía a través de la investigación extensiva no está exento de problemas. En ningún caso, en la formación del filósofo, este puede ser el único concepto de historia válido, incluso si su justificación como investigación es mucho más sólida. La historia filosófica de la filosofía sigue siendo necesaria. De alguna manera, aparece como el resguardo y el antídoto contra la irrelevancia conceptual de la investigación, de lo cual el ejercicio de la historia histórica de la filosofía no es el único culpable. De este modo, se necesita un criterio no investigativo que justifique la presencia de esta vieja concepción de la historia de la filosofía en el aprendizaje de la filosofía. Solo si da este reconocimiento a la historia filosófica de la filosofía, se podrá evitar que esta siga utilizando criterios directamente extravagantes para justificarse como investigación. 
Por otra parte, ¿la historia histórica de la filosofía puede justificarse de modo filosófico o su inclusión es solo estratégica? Incluso si la historia histórica de la filosofía es más histórica que filosófica y sus operaciones son más cercanas a las del historiador que a las del filósofo, también puede beneficiar directamente al filósofo. Del mismo modo que la formación del físico necesita matemáticas y la del biólogo, química, el filósofo necesita historia de la filosofía en un sentido histórico. El pensamiento postmoderno establece que todo conocimiento está históricamente mediado, que no existe la posibilidad de elevarse absolutamente de las condiciones sociales, temporales y culturales desde las que una filosofía es formulada. Esta postura puede sonar muy abstracta y se puede entender como una negación completa de la posibilidad de alcanzar cualquier tipo de pensamiento universal. Existe un aspecto, sin embargo, en que esta mediación histórica parece más fácilmente asumible. Cada época histórica asume como filosóficas un número muy pequeño de cuestiones. La historia histórica de la filosofía sirve para esclarecer este punto y entregarle algo de amplitud a la autoconcepción que la filosofía tiene de sí misma en cada momento histórico. Parece que solo un historiador no normativo de la filosofía podrá recordar al filósofo que lo que hoy considera como un tema propiamente filosófico -la relación entre matemáticas y gobierno, la existencia de Dios, la inmortalidad del alma o la teoría racial- siguientes generaciones las considerarán absolutamente irrelevantes desde una perspectiva filosófica.

La historia histórica de la filosofía ocupa un lugar intermedio. Aunque cada vez está más liberada, todavía siguen influyendo doscientos años en los que la hermana filosófica ha insistido en su minoría de edad. Por este motivo, no solo cuando se defiende, sino también cuando se entiende a sí misma, lo sigue haciendo como si fuese una rama de la filosofía. Esta defensa carece de sentido hoy. Por un lado, consigue, con mayor brillantez que la historia filosófica de la filosofía, el reconocimiento de la investigación. Además, en un momento donde grandes sectores de la filosofía se han encerrado en una hiperespecialización aún más irrelevante desde un punto de vista filosófico, una disciplina como la historia de la filosofía representa una de las pocas herencias del humanismo en la academia contemporánea. Se trata de una de las disciplinas más interdisciplinarias y ricas en el campo de humanidades: si su método es histórico, las exigencias de su objeto obligan al historiador de la filosofía a una enorme destreza filosófica para elaborar un producto apreciable. 8

${ }^{8}$ Agradezco los comentarios que Luciano Venezia, Daniel Mansuy, Álvaro Cortina y Lourdes Flamarique han hecho a versiones previas de este artículo. 


\section{BIBLIOGRAFIA}

Collins, Jeffrey. "Quentin Skinner's Hobbes and the Neo-Republican Project." Modern Intellectual History vol.6, ํ3 (2009): 343-367.

Hankins, James. "The significance of Renaissance philosophy". En The Cambridge Companion to Renaissance Philosophy, de James Hankins. Cambridge: Cambridge University Press, 2007: 338-345.

Hegel, G.W.F. Lecciones sobre historia de la filosofía. México: FCE, 1996.

Koselleck, R. "Sobre la necesidad teórica de la ciencia histórica" in Prismas. Revista de historia intelectual, XIV, 2010, pp. 137-148

Koselleck, R, Sentido y repetición en la historia. Buenos Aires: Hydra, 2013.

Llano, Alejandro. Olor a yerba seca. Madrid: Encuentro, 2008.

Manzo, Silvia. "Piezas de un modelo para armar, desarmar y rearmas. Autores, textos y temas en la construcción de cánones filosóficos." En La modernidad ayer y hoy, de Susana Maidana y María Risco. Tucumán: Universidad Nacional de Tucumán, 2017: 117-146.

Mondolfo, Rodolfo. Problemas y métodos de investigación en la historia de la filosofía. Buenos Aires: Eudeba, 1960.

Morgan, Michael. "The goals and methods of the history of philosophy." The Review of Metaphysics vol.40, $\mathrm{N}^{\circ} 4$ (1987): pp. 717-732.

Narbonne, Jean-Marc. “De la dualité structurelle de l'histoire de la philosophie: les enjeux d'un controverse." En Comment écrire l'histoire de la philosophie, de Yves Zarka. París: PUF, 2009: pp. 59-78.

Ortega y Gasset, José. "Prólogo a Historia de la filosofía de Émile Brehier." En Obras completas vol. VI, en José Ortega y Gasset. Madrid: Taurus, 2006: pp. $135-171$

Pitkin, Hanna. Fortune is a Woman. Gender and Politics in the Thought of Niccolò Machiavelli. Chicago: The University of Chicago Press, 1984.

Rabossi, Eduardo. En el comienzo Dios creó el canon. Biblia berolinensis. Buenas Aires: Gedisa, 2008.

Schopenhauer, Arthur. "Sobre la historia." En El mundo como voluntad y representación. Complementos, de Arthur Schopenhauer, 490-498. Madrid: Trotta, 2003.

Sorell, Tom. "Pertinence et limite de la caricature en histoire de la philosophie: le cas de Descartes." En Comment écrire l'histoire de la philosophie, de Yves Zarka. París: PUF, 2001: pp. 113-129.

Zarka, Yves. "Que nous importe l'histoire de la philosophie?" En Comment écrire l'histoire de la philosophie, de Yves Zarka.París: PUF, 2001: pp. 19-32. 